The University of San Francisco

USF Scholarship: a digital repository@ Gleeson Library |

Geschke Center

2018

\title{
Modeling resident spending behavior during sport events: Do residents contribute to economic impact?
}

\author{
Nola Agha \\ University of San Francisco, nagha@usfca.edu \\ Marijke Taks \\ University of Ottawa, marijke.taks@uottawa.ca
}

Follow this and additional works at: https://repository.usfca.edu/sm

Part of the Sports Management Commons

\section{Recommended Citation}

Agha, Nola and Taks, Marijke, "Modeling resident spending behavior during sport events: Do residents contribute to economic impact?" (2018). Sport Management. 21.

https://repository.usfca.edu/sm/21 
Running head: MODELING RESIDENT SPENDING DURING SPORT EVENTS

\title{
Modeling Resident Spending Behavior During Sport Events: Do Residents Contribute to Economic Impact?
}

\author{
Nola Agha \\ Marijke Taks
}

March 19, 2018

\begin{abstract}
The role of residents in the calculation of economic impact remains a point of contention. It is unclear if changes in resident spending caused by an event contribute positively, negatively, or not at all. Building on previous theory we develop a comprehensive model that explains all 72 possible behaviors of residents based on changes in (a) spending, (b) multiplier, (c) timing of expenditures, and (d) geographic location of spending. Applying the model to Super Bowl 50 indicates that few residents were affected, positive and negative effects were relatively equivalent, thus their overall impact is negligible. This leaves practitioners the option to engage in the challenging process of gathering data on all four variables on all residents or to revert back to the old model of entirely excluding residents from economic impact. From a theoretical perspective, there is a pressing need to properly conceptualize the time variable in economic impact studies.
\end{abstract}

Keywords: economic impact, cost benefit analysis, crowding out, mega event, mega sport event 
Modeling Resident Spending Behavior During Sport Events: Do Residents Contribute to Economic Impact?

Positive economic impacts of large scale sport events, as well as the methods for measuring economic impact have come under scrutiny (e.g., Késenne, 2012). Nevertheless, sport event managers, local organizations, and public authorities still rely on economic impact studies to justify the public spending which is often required to cover the high cost of organizing events. It is therefore imperative that they can rely on trustworthy economic impact studies. One question that continues to arise is whether residents should be included in economic impact. To answer this question we do not conduct an economic impact study. Instead, we examine the theory behind economic impact, build a model, and apply it to a large event to answer a critical question about the methods currently used to conduct these studies.

Traditionally, resident spending was not considered in the calculation of economic impact (Getz, 1991; Crompton, 1995). Over time, researchers identified, categorized, and labeled exceptions to this rule and excluded or included residents if they were Home stayers, Runaways, Changers, or exhibited other forms of non-traditional behavior (e.g., Coates \& Depken, 2009; Cobb \& Olberding, 2007; Preuss, 2005). These previous studies mainly focused on eventaffected residents who were surveyed at events. Yet, as Matheson and Baade (2006) stated, “A basic shortcoming of typical economic impact studies, in general, pertains not to information on spending by those included in a direct expenditure survey, but rather to the lack of information on the spending behaviour for those who are not" (p. 356). In other words, we have some understanding of the role event-affected residents play in the calculation of economic impact (e.g., Kwiatkowski, 2016), but we do not understand the role of residents that are not involved in the event but may still be affected by it. Previous research has indeed indicated residents who do not engage with the event may change their spending by staying home (e.g. Coates \& Depken, 
2009), going out, or otherwise altering their behaviors (e.g., Crompton \& Howard, 2013, Preuss, 2005; Taks, Girginov, \& Boucher, 2006).

Ultimately, the current conceptualizations of "other" types of residents are incomplete. There is no model that encompasses the universe of possible behavioral and spending changes incurred by residents who are affected by events (e.g., disrupted, stimulated, diverted) that then lead to either a positive, negative, or neutral charge to the total calculation of economic impact. Therefore, the primary purpose of this paper is to develop a model that explains all of the possible ways residents' changes in behavior can affect impact. Furthermore, primary data collected during a Type B event (Gratton \& Taylor, 2000) are used to illustrate an application of the model and to determine if the overall effect of residents is positive, negative, or neutral. Type B events are defined as "Major spectator events generating significant economic activity, media interest and part of an annual cycle of sport events" (Gratton \& Tylor, 2000, p. 190).

This contribution clarifies a major point of contention, namely whether or not to include resident spending in economic impact studies based on a direct expenditure approach (DEA; Davies, Coleman, \& Ramchandani, 2013) or a cost benefit analysis approach (CBA; Késenne, 2012; Taks, Késenne, Chalip, Green, \& Martyn, 2011). The question of whether and how residents affect economic impact is also important for event managers, local organizations, and public authorities, who continually read, conduct, and evaluate survey-based economic impact studies and use them as a currency to justify their public spending.

\section{Residents in Economic Impact Studies}

Economic impact studies based on a DEA engage in a series of steps to measure new spending in a local economy due to an event. This includes surveying spectators and/or participants and asking a series of questions regarding their status as a visitor or local resident, 
how much they spent, how long they are visiting, etc. Traditional methods excluded all residents' spending due to the idea that these expenditures would occur locally regardless of the presence of an event and these expenditures simply substitute for others (e.g., Crompton, 1995). Over time, ad hoc attempts identified the ways residents might have a non-neutral effect on impact (see Table 1) and authors like Gelan (2003) advocated for including resident spending, although the mistake in this approach is that it only analyzed residents who were event spectators, not all residents. CBA, on the other hand is based on welfare economics and views each dollar as a cost or benefit and thus results in a calculation of net economic benefits (Késenne, 2012). In a framework developed by Agha and Taks (2015), residents have the ability to add to impact (e.g., residents tapping into their savings because of the event) or to take away from it (e.g., event is crowding out residents or crowding out local businesses). A CBA has some similarities to a DEA in that it includes a survey-based approach to measure specific gains (or losses) to the local economy because a researcher must know how locals are changing their behaviors and spending to determine if it generates a benefit or a cost.

[insert Table 1 about here]

Table 1 provides an overview of research that has labeled various categories of residents that should be accounted for in economic impact studies. The types of changes in behaviors described in these studies are rather limited and various names have been given to describe the same behavior. Note that the conceptualizations of resident impact in Table 1 define eventrelated changes, or shifts, in two different variables, the timing (Changers and Home stayers) and geographic location of the money spent (Home stayers and Runaways). These studies do not take into consideration possible shifts in the amount or businesses where the money is spent. In the next section, we propose a model using four variables that captures many more possible ways in 
which residents may shift their spending behaviors because of an event. In doing so we demonstrate that these previous categorizations are insufficient to capture the real economic outcome of changes in resident spending behavior due to event hosting.

\section{Model Development}

Economic impact is new spending in a local economy less any expenditures that have left the local economy due to the event in question. At a basic level, expenditures made locally from residents who would have otherwise made those expenditures are considered a reallocation of funds and do not generate benefits or costs (Table 2). From this simplistic definition we see the amount spent and the geographic location of the spending are the first of four necessary variables that need to be considered. We also see that economic impact implicitly takes into account two cases that capture a shift - the actual spending and the alternate spending that would have occurred without the event. In Table 2 these two variables and the two cases are interacted: the geographic area where the money is normally spent in the absence of the event (i.e., "origination of expenditures"), and where the money is actually spent because of the event (i.e., to the "location of expenditures"). The third variable that needs attention is the business industry in which spending occurred in order to derive a multiplier that will estimate the indirect and induced effects of the initial spending (Crompton, 1995). The fourth variable, the timing of the expenditure, is not nearly as straight forward as the first three. This is due to competing frameworks, limited research in this area, and ad hoc operationalization of the variable. For instance, there is no consensus which time frame should be considered. In the context of the Olympics, tourism spending can change several years before an event (Solberg \& Preuss, 2007). With no sense of time scale, direct surveys questions ask did you "reduce spending in the past" or "reduce spending in the future" or will you "re-spend at a later date" while questions designed 
to find Home stayers ask "Did you forgo another vacation (trip) in order to attend the [event]?" (Preuss, Kurscheidt, \& Schütte, 2009). In short, there is very little alignment between theoretical models (conceptualizations) of time shifted expenditures and the survey questions that are designed to identify those shifts. Our solution is three-pronged: (1) we acknowledge time as a theoretical necessity in calculating economic impact and build it into our model; (2) we rely on current survey-based questions to identify time-shifted behaviors (Home stayers and Changers) and test those against an improved four-variable conceptualization of shifted spending; (3) we collect qualitative data on time shifting to see if it aligns with multiple choice questions.

In summary, there are four necessary variables related to economic impact: the amount spent, the geographic location of spending, the business industry in which it was spent (to derive the multiplier), and the timing of the expenditure. To calculate impact one must capture the shift in these variables. For example, a resident can spend more, less, or the same amount of money in the presence of an event in the host region. A resident can spend within the geographic area of impact or outside of it. Spending can shift to a business with a higher multiplier, same multiplier, or lower multiplier. Finally, spending can occur as normally planned or a resident may shift the timing of their expenditures to before or after the event ${ }^{1}$.

Given these four variables and their associated shifts, Table 3 illustrates there are 18 potential behaviors for the case in which a resident intended to, and did, spend their money locally (i.e., In-In). For example, an event can cause a resident to spend the same amount but at a lower multiplier business which will have a negative effect on impact. An event can cause a resident to spend more at a higher multiplier business which will lead to economic benefits regardless of whether the spending is time shifted or not.

[Insert Table $2 \& 3$ about here] 
From Tables 2 and 3, it is apparent that the geographic variable has multiple dimensions which generates four distinct cases for residents:

- In-In: Spending that would have been spent in the area of impact and stayed in the area (the cases illustrated in Table 3).

- In-Out: Spending that would have been spent in the area of impact but shifted out. All of these 18 cases are negative and are analogous to the Economic Cost in Table 2. Runaways would be classified here but so would a resident who intended to go to the local golf course but it was booked for a pre-event tournament and instead drove to a nearby course that was outside of the area of impact.

- Out-In: Spending that would have been spent outside the region but shifted in. These 18 cases are all positive and correspond the Economic Benefit in Table 2. A Home stayer is a special case of this.

- Out-Out: Spending that would have been outside the region and stayed outside the region. These 18 cases are not related to economic impact. They include Changers, but also residents who planned to take a day trip to visit family in a nearby metropolitan area and did, in fact, take that planned trip.

The outcomes based on shifts in geography related to In-Out, Out-In, and Out-Out are straight forward, but the shifts in behaviors within the specific area, In-In, need to be accurately modeled and estimated. Moreover, the cases in Table 3 illustrate three important points.

1. Economic impact can be affected regardless if residents are positively or negatively affected by the event (e.g., a resident spending more than usual on public transit to attend the event, or a resident forced to spend more on public transit because of eventrelated traffic). As illustrated here, it is possible, although not necessary, for positive 
and negative engagement to have the same effect (in this case, higher spending on public transportation).

2. The changes in behavior can begin with any of the four variables. For example, a resident may stay away from downtown because of traffic (geography), a resident may purchase tickets for the event (spending), a resident may go grocery shopping on Thursday to avoid weekend crowds (timing), or a resident may buy lunch from a grocery store instead of going to her normal deli for lunch (business).

3. Regardless of where it begins, the initial disruption can (but does not necessarily have to) affect the other three variables. We provide two examples of how multiple variables can be affected and illustrate which variables shift: (a) a resident may purchase tickets for the event, which could be more than she normally spends on entertainment and in a different location. She makes up for it by not going out for movies the following week. This is a shift in location, timing, business multiplier, and spending; (b) a resident may go grocery shopping on Thursday instead of his normal Sunday shopping, but he spends more because he went to a different store in a different city (within the area of impact) on his drive home from work. This is a shift in timing and spending, but the location and business multiplier are the same.

Of the 18 possible behaviors for the In-In group, five outcomes are positive, five are negative, four are neutral (no effect), and four are indeterminate. The cases of higher spending at lower multiplier businesses and lower spending at higher multiplier businesses make it clear that all four variables are necessary to calculate the final impact as these are indeterminate, ex ante, and require the actual values on a case by case basis to determine their effect.

Based on the framework presented in Table 3, we can see there are 72 possible behavioral 
combinations of which 22 have no effect on economic impact, 23 are positive, 23 are negative, and 4 are indeterminate. Thus, in order to determine the overall impact of residents we must know: (a) the shift in spending, the shift in business, the shift in time, and the shift in geography; and, (b) the proportion of residents in each of these categories. Because mega-events generally assume a large area of impact, we hypothesize most resident geographic spending shifts will be within the host region (i.e., In-In) and thus subject to the variable impacts presented in Table 3.

\section{Study Context}

Super Bowl 50, the 2016 championship game for the National Football League (NFL), was hosted in the San Francisco Bay area and allowed for applying the model to different groups of residents from three distinct geographical perspectives (see Figure 1). The Super Bowl is traditionally the largest one-day sporting event in the U.S. in terms of viewership with 111.9 million viewers in 2016 (Nielsen, 2016). The Super Bowl 50 Host Committee defined the area of impact (i.e., geography variable) as the 6,900 square mile, nine-county San Francisco Bay Area (population 7.15 million). This nine-county Bay Area as whole was the first geographic area we delineate for our study. The region is comprised of three major cities, San Francisco (pop. 805,235), Oakland (pop. 390,724), and San Jose (pop. 945,942), and 98 smaller municipalities (Bay Area Census, 2016). Host Committee consultants reported 1.9 million residents and 300,000 out-of-area visitors attended a Super Bowl related event (Repucom, 2016) although the game itself was played in front of only 70,000 fans at Levi's Stadium in Santa Clara. Seven miles away from Levi's Stadium, the city of San Jose hosted several community events as well as the NFL Opening Night at SAP Center where 7,000 fans paid to watch the media interview players (Davidson, 2016). Santa Clara County, which includes the cities of San Jose and Santa Clara, was the second geographic area taken into consideration. 
San Francisco, 45 miles away from Levi's Stadium, hosted the majority of the lodging and hundreds of hospitality events located primarily in the downtown central business district. Two main fan festivals were also in San Francisco. Super Bowl City was a free, 9-day fan festival featuring 64 free performances with attendance estimates ranging from 5,000 per day (Lee, 2016) to a total of 900,000 ("Super Bowl”, 2016). The NFL Experience was a paid fan experience that reported 150,000 attendees over 9 days (Controller's Office, 2016) and was located at the Moscone Center; ticket prices ranged from $\$ 25$ to $\$ 60$.

Super Bowl City was located above the region's busiest public transit station and required the closure of over 14 streets, the re-routing of 20 bus lines, and the closure of one streetcar line for a total of 21 days (SFMTA, 2016). The NFL Experience was located less than a mile away from Super Bowl City and both events were located within one mile of all six of San Francisco's Fortune 500 companies, two of which were asked to have their employees work from home during Super Bowl City (Raymos, 2016). Similarly, the city of San Francisco encouraged residents to, "Work remotely, stagger your work hours or take that vacation you deserve" (SFMTA, 2016) $)^{2}$. In short, the bulk of the activity and disruption (non-game related events) were held in a small portion of downtown San Francisco, for multiple days. We expected the vast majority of resident disruption to be related to San Francisco and not Santa Clara where the game was played. San Francisco County was the third geographic area under consideration.

[Include Figure 1 about here]

Super Bowl 50 was somewhat different from other Super Bowls in that it was geographically dispersed in a warm weather city with a developed public transportation system. On the other hand, Super Bowl 50 is highly comparable to other Super Bowls and to many other large events on other event features such as: high levels of security, a multitude of hospitality 
events, crowding out of non-event visitors (it occurred during Chinese New Year), fan events, the closing of the central business district, altering public transportation, residents asked to stay home, geographic dispersion (similar to the Olympics or Commonwealth Games), thousands of visitors, public subsidies, etc. Thus, Super Bowl 50 has event features that make it generalizable to many other Type B events (Gratton \& Taylor, 2000) throughout the world.

\section{Method}

\section{Survey Instrument}

We used a survey method (using the Qualtrics platform) similar to traditional DEA impact studies to collect the data on residents' spending behavior. The survey was pre-tested multiple times to develop the clearest questions for respondents. We integrated the standard questions to identify the three categories of Home stayers, Changers, and Runaways, and added questions to capture all of the 72 categories.

A screening question first identified whether the respondent was a Bay Area resident and then recorded their zip code. Non-Bay Area residents were exited from the survey. The zip code determined to which of the three geographic areas the resident belonged. Next, a series of questions determined whether the respondent was aware of the Super Bowl, if they were attending, and if so, how much they were spending on the event. Similarly, respondents were asked if they were aware of the fan-related events, if they were attending, and if so, how much they were spending.

The following section captured spending information. Specifically, respondents were asked to record their actual spending all day "yesterday" using three variables: the amount of spending, the business, and the city in which each expenditure took place. Next, they were asked if the Super Bowl or its related events caused them to change the amount and/or location of their 
spending yesterday. If they believed their spending yesterday was affected by the Super Bowl they recorded the amount, the business, and the city of each of what their expenditures would have been in the absence of the event, allowing for the capture of changes in dollar amounts spent, multipliers, and geography.

In imagining what their behaviors would have been in the absence of the event, respondents relied or either known or hypothetical information. For example, in some cases the alternate activity was known (traffic was terrible so someone took public transportation instead of Uber), sometimes it was partially known (someone planned to go out to dinner but the restaurant was near a busy event zone so they stayed home and ate dinner - the cost of staying home exists but is generally not acknowledged), and was sometimes completely unknown and responses were hypothetical (someone definitely spent money to visit a fan festival but without it they honestly did not know what they would have done or how much they would have spent that Saturday afternoon).

In order to determine timing changes, all respondents were asked the screening question, "Because of the Super Bowl or its related events, was your total spending amount yesterday: the same as usual, more than usual, or less than usual". The three responses were randomized so as not to lead respondents in any direction. If a respondent spent more or less than usual they were asked the amount and then received a follow up question on the timing of their expenditures. Those who spent more than usual were asked the source of their additional funds: their savings, borrowed money (for example, a credit card), reducing spending in the past, or reducing spending in the future. Those who spent less than usual were asked if they would re-spend at a later date in the Bay Area, re-spend at a later date outside the Bay Area, or save.

To identify Home stayers, Runaways, and Changers, all respondents (not just those who 
had indicated they were affected) were asked if they were taking a vacation away from the Bay Area between January 30 and February 7. Those who responded positively were asked follow up questions to determine if they were leaving because of the Super Bowl (Runaways) or foregoing another vacation at a different time to take a vacation during the Super Bowl (Changers).

Additionally, they were asked if they were renting out their home on Airbnb or a similar service and how much they were earning. Those who responded they were not taking a vacation during the Super Bowl period were asked if they were foregoing a vacation (at a different time) in order to stay and attend the Super Bowl or its associated events (Home stayers).

All respondents were asked if they lived or worked near four primary event zones: Moscone Center in San Francisco, Justin Herman Plaza/Ferry Building in San Francisco, Levi’s Stadium in Santa Clara, and SAP Center in San Jose. Demographic questions included gender identity, age (in years), and annual household income (15 categories). To capture a respondent's attitude towards the Super Bowl, data was collected with the Sport Involvement Inventory based on Shank and Beasley (1998), using a seven-point, eight-item sematic differential (e.g., boring vs. exciting, uninteresting vs. interesting, etc.). Finally, respondents were asked to share any additional comments regarding the amount, timing, and location of their spending changes due to the Super Bowl and its associated events.

\section{Data Collection and Participants}

When survey populations are geographically and demographically diverse Yun and Trumbo (2000) recommend using multi-mode techniques to improve sample representativeness. For that reason, we collected data throughout the 6,900 square mile area in a variety of ways. First, thirty-two graduate students enrolled in a research methods course were enlisted to probabilistically sample (Jones, 2015) the nine-county Bay Area in person for the nine days 
surrounding the Super Bowl by intercepting subjects at six similar, pre-determined locations in each county (public transit station, low-price-point grocery store, high-price-point grocery store, coffee shop, laundromat, and a strip mall or a busy shopping street in a big city). To achieve a geographically stratified sample, counties were sampled in approximation to their overall portion of the Bay Area population (see the percentages in Figure 1). Second, given the complexity of surveying such a geographically distributed area, during the nine-day collection period 33 graduate students enrolled in a different research methods class distributed the survey online through 33 different, hyperlocal, digital news publications that covered news related to Super Bowl 50. Third, to counter concern that we would over-sample residents who were familiar with or interested in the event we targeted residents in the Bay Area who would take our questionnaire when shared on various convenient digital platforms. Finally, a sampling concern was related to obtaining accurate spending information given that the survey only captured a single day of behavior and given that respondents are often hesitant to respond to questions about money (Swan \& Epley, 1981). To address these concerns we utilized a longitudinal convenience panel (also stratified by county population) that was tracked over the nine-day data collection period using an electronic diary method known to provide more accurate data than onsite surveying (Breen, Bull, \& Walo, 2001). Each panel respondent received the full online survey on the first day and a shortened online version that collected only spending information on subsequent days.

There were 1,227 surveys taken of which only 790 were completed ${ }^{3}$. A further 151 surveys were discarded because the reported spending information (in dollar amounts) was not complete or was not in alignment with the follow up question of whether they spent more, the same, or less. Table 4 indicates the descriptive statistics of the samples for each geographic sample - the nine-county Bay Area with respondents from all samples $(n=572)^{4}$, San Francisco 
County ( $\mathrm{n}=127)$, and Santa Clara County $(\mathrm{n}=141)$ in terms of gender, household income, attitude, age, and awareness of the event. The samples were highly representative of the region regarding age and income distribution (https://censusreporter.org/profiles/). At a 95\% confidence level, the confidence intervals were $4.1 \%$ for the Bay Area sample, 8.7\% for San Francisco, and 8.3\% for Santa Clara (Griffiths, Hill, \& Judge, 1993).

[Insert Table 4 about here]

\section{Coding and Data Analysis}

The survey collected shift data for the time variable through multiple choice questions. For the spending, business, and geographic location variables, actual and alternate values were collected to generate the shifts. First, the location of the business was translated into a county code and business variables were assigned an output multiplier ${ }^{5}$ from IMPLAN ${ }^{6}$ based on the appropriate industry ${ }^{7}$. Next, variables were coded into their respective shifts: spending more, less, or the same was determined by evaluating actual and alternate spending; a business multiplier that was higher, lower, or the same was determined by the actual and alternate businesses; spending that was In-In, In-Out, Out-In, or Out-Out was determined by evaluating the county codes for the location of the actual and alternate spending. All of this coding was performed separately for the three different areas of impact, and observations were assigned to these areas according to their zip code.

\section{Results}

We present the results for each of the geographic areas of interest, for individual variables, two variables, three variables, and all four variables.

\section{Spending}

Depending on the geography $76-84 \%$ reported their spending amounts to be unaffected 
by the Super Bowl (see Table 5). Of the remainder, more respondents reported spending more than spending less except in San Francisco. The average amount spent more and spent less varied across geographic samples.

[Insert Table 5 about here]

\section{Business}

Overall, the vast majority of respondents spent at businesses with the same multiplier (see Table 5). While the average multiplier in the geographic samples was roughly the same, the shifts in multipliers were negative in the Bay Area and Santa Clara samples. The positive change in multiplier in San Francisco stems from the behavioral shift towards public transportation which has one of the highest multipliers.

\section{Time}

Residents classified as Changers are those whose behaviors have shifted on only the dimension of time. The results show they are less than $1 \%$ of the Bay Area population. Similarly, in the open-ended feedback very few respondents reported shifting the timing of their expenditures on the day in question or on other days during the Super Bowl period (see the lines labeled "Qualitative" in Table 5). The most common descriptions of time shifts were for residents changing the timing of doctor appointments and other meetings to avoid traffic and crowds. In the overall framework of economic impact, changing the timing of an appointment is an example of a behavioral disruption that begins with time (and does not affect amount, business, or geography) whereas traditionally the timing variable is intended to capture deeper shifts in expenditure timing (e.g., spending more now on tickets to events and less later on local leisure consumption). The qualitative feedback listing only these time-disrupted activities begs the questions of whether the right questions are being asked and if people are even capable of 
truly answering time shifting questions. Certainly, people have a general sense that they are being affected by these different variables but it is not clear that the data can capture these shifts.

\section{Geography}

The majority of residents in all geographic areas spent their money within the area of impact and had intended to do so regardless of the event (Table 5). In addition, In-Out and OutIn behavior is quite uncommon. Open-ended comments revealed that residents perceived their spending to shift away from the area more often than reported in their spending data. Generally, more people reported shifting spending away from event-related areas than towards them.

\section{Spending $\mathbf{x}$ Business}

Whereas the values in Table 5 reflect the difference of how much more or less was spent, the values hereafter represent the more precise case of the actual spending times the multiplier less the alternate spending times a multiplier for all reported transactions, and then averaged across respondents. The interaction of the spending shift and the multiplier shift in Table 6 reinforce the results from the spending section. The most important finding is the overall negative effect in San Francisco where more people are spending less than spending more and the amount less is greater than the amount more. In the other areas, the reverse is true and a greater number of residents are spending more. Note that when less is spent in higher multiplier businesses, the overall effect remains negative. Given the much higher spending values in the spent more category, we point to research showing that we remember larger expenditures (Neter \& Waksberg, 1964) whereas the alternate case, spending less, is both hypothetical and harder to remember. This suggests that the spent less values may be underestimated.

[Insert Table 6 about here]

\section{Spending x Time}


A single question was asked to identify if those who spent more, time shifted their behaviors. Of those who spent more than normal, the proportion of time shifting ranged from $50 \%$ in the Bay Area sample to $22 \%$ in the San Francisco sample (see Table 6). These timeshifted expenditures should be disregarded for economic impact (unless the multiplier of the business is taken into account, however, as can be seen from the multiplier analysis (Table 5) there is no substantial shift in the actual and alternate multiplier). In contemplating the reliability of these results, we do wonder, do respondents really know what their time shifts will be? Given that spending more in the past or future requires pondering one's budget and expenditures, we are not confident that the majority of people know or track this kind of behavior.

\section{Spending x Geography}

Table 6 indicates that adding geographical shifts to net changes in spending $\mathrm{x}$ multiplier provides different estimates than in Table 5 which reports only spending. In the geographic samples, the amount spent less and the amount spent more have higher average values once geographic shifts are considered. We use this to highlight the importance of including all variables because an estimate of economic impact based on spending without geographic location would have been incorrect as the In-Out and Out-Out expenditures would have been erroneously included as positive gain in the calculations.

\section{Time x Geography}

The effect of Home stayers on impact is positive, but there are more Runaways (negative) in Table 5 than Home stayers (Table 6). Note, however, that the numbers are low confirming that these behaviors do not greatly impact shifts in economic impact.

\section{Spending x Business x Geography}

The interaction of three variables in Table 7 paints a different picture than does the 
analysis of one or two variables. Both In-Outs and Out-Ins are negligible in size perhaps suggesting that surveyors shouldn't spend time capturing Runaways and Home stayers or other forms of geographic shifts. Santa Clara County does appear to have more In-Outs and Out-Ins than the other areas. Note that the average In-Out shift of $\$ 106.70$ in Santa Clara County is a loss as this money was shifted out of the area. On the other hand, Out-Ins represent money that was shifted in and generate a positive impact. In the case of Santa Clara County the Out-Ins spent $\$ 17.19$ less than usual, but this was still a gain to the county (without time shifting) and is still positive, as expected.

[Insert Table 7 about here]

\section{Spending x Time x Geography}

Of those who spent less than normal, a single question determined their time and geographic shifts. Few plan to re-spend later outside the Bay Area suggesting that reductions in spending are mostly retained locally (Table 7).

\section{Spending x Business x Time x Geography}

When time shifting is included to analyze all four variables simultaneously, the total responses drop because time shifting does not matter for those whose spending behavior was the same (which ranged from 59\%-83\% of the samples in Table 8). Only respondents who reported spending more or less provided information on their time shifting behaviors and of these respondents, few answered the time shifting question.

\section{[Insert Table 8 about here]}

From this, we derive two important conclusions. First, in Table 8 only a small portion of residents engage in behavior that leads to a change in impact. In the case of the entire Bay Area only $0.2 \%$ of respondents engaged in In-Out behavior and $7 \%$ engaged in In-In behavior that 
affected impact. In San Francisco, the geographic area most impacted by the event, the results are similar: $0.8 \%$ were Out-In and $11.2 \%$ were In-In with behaviors that affected impact. Second, when the fourth variable for time is brought in, the average values for each type of behavior shift from the values in Spending x Business x Geography-analysis in Table 7. This further reinforces the point that any estimate of economic impact performed with values from one, two, or three variables will be incorrect.

\section{Discussion}

Using the model based on shifts in four spending dimensions, we found In-In residents exhibited all 18 forms of behavioral shifts in spending, multiplier, and time. On the other hand, we found In-Out and Out-In behavior to be exceedingly rare, except in the case of Santa Clara County. We find this unsurprising since the county is a smaller subset of a major metropolitan area whose county lines are indistinguishable in the physical landscape leading to higher rates of cross-border transactions ${ }^{8}$.

The application of the model to an event allowed us to demonstrate that using one, two, or three variables resulted in incorrect estimates of resident impact. Moreover, we illustrated that respondents were unwilling or unable to answer questions on time shifts and qualitative responses indicated that respondents viewed time shifting differently (short term) than academic conceptualizations of the variable (to pre- or post-event periods). Finally, the model included four indeterminate categories of In-In residents (in Table 3). We found the multiplier effect was not stronger than the spending shift in the cases of higher-spending+lower-multiplier or lowerspending+higher-multiplier. Thus, although these situations are hypothetically indeterminate, the model can be simplified by assuming that the higher-spending+lower-multiplier has a positive effect and the lower-spending+higher-multiplier has a negative effect. This means that of the 72 
possible behavioral combinations, 22 have no effect on economic impact, 25 are positive, and 25 are negative.

\section{Are resident effects positive, negative, or neutral?}

To determine if the overall effect of residents is positive, negative, or neutral we note that the value of impact is a function of the definition of the area of impact. In this exercise we looked at three geographic areas: the entire metropolitan area, the county where the game was hosted, and the county where the vast majority of the Super Bowl week activities were held. Those counties, Santa Clara and San Francisco, saw the highest percentages of residents who were affected and reported shifts in behaviors. San Francisco had more residents spend less than more. The decline in spending from those spending less was larger in magnitude than the increased spending from those spending more, resulting in an overall net decrease. Santa Clara saw an increase in In-Out behavior of residents shifting their spending outside the county; thus resident behavior decreased economic activity. As illustrated in Table 9, we found San Francisco, the event area with the most disruption and activity, to be most negatively affected. Note that the three areas under investigation represent three different event- and city-size contexts (e.g., Agha \& Taks, 2015): a multi-day event concentrated in a central business district (San Francisco County), a single day event in a suburban city (Santa Clara County), and an annual, week-long mega event in a large metropolitan area (Bay Area). From this perspective, a large event in a small area of impact had a more negative impact (10\% of San Francisco residents leading to negative impact) compared to a large event in a large area of impact ( $2 \%$ of Bay Area residents leading to negative impact).

[Insert Table 9 about here]

Although the purpose of this research is not to conduct an economic impact analysis, the 
natural inclination of a researcher is to extrapolate the values in Table 8 to the entire area to generate an overall effect of residents. This would be incorrect because if we applied the percentages in Table 9 to the entire population, we would be suggesting that every person (including babies, children, seniors, and the unemployed) engaged in these spending behaviors, clearly leading to an overestimation. Using the number of households in each geographic region could lead to similar inaccurate results as a single household could include one member who spent more, one who spent less, and one who was unaffected.

Even without an exact value for resident impact for this event, the results from the application of the model clearly support the proposition that some local residents are crowded out during an event (Késenne, 2012). We also found evidence of retained expenditures. Most importantly, we found that they are roughly equivalent with slight differences based on the area of impact, essentially neutralizing the overall impact.

Although our research is framed around the DEA and CBA survey-based approaches to impact, the quantitative results indicate important implications for the ex post approach that is common in the sports economics literature. Possible explanations for the negative or neutral effects of the Super Bowl and other large events (e.g. Baade, Baumann, \& Matheson, 2008; Matheson \& Baade, 2006) are crowding out of both visitors and locals. The neutralizing behaviors of residents confirm that these non-positive ex post results are unlikely to derive from local crowding out of residents.

\section{Limitations and Future Research}

Although it is theoretically possible and conceptually simple to gather information on all residents to compute an impact, Wilton and Nickerson (2006) agree "the actual collection of such information is extremely difficult" (p. 17). For instance, capturing all shifts in all four 
variables was very challenging and we acknowledge there are known imperfections in collecting survey data (Ritchie, 1984). Despite testing multiple variations of our instrument, there were several indications that it did not precisely capture all behaviors. For example, the open-ended qualitative responses indicated that respondents are better able to remember or identify higher expenditures despite a perception of a shift to lower spending. We also found evidence that humans are hesitant to share information pertaining to money (Furnham \& Argyle, 1998).

Capturing residents' actual activity on a previous day as well as any activity that was different from what would have occurred, allowed us to identify intertemporal effects. There was a high non-response rate when asking respondents if changes in spending (reduced or increased) is at the benefit/expense of the past or future, or if they have saved/spent or plan to re-spend or save the money in the future. Respondents struggled to know, understand, or properly evaluate time shifting behavior. There is an important need for future research on time shifting - clearly defining it, deciding what time period matters, and finding ways to ask appropriate questions so respondents can both understand and correctly answer. Journaling expenses over a certain period of time could be an alternative way to capture this.

To gather the required information with a large enough number of responses, we used a variety of data collection techniques. Based on the number of Super Bowl game attendees it appears we oversampled people who purchased Super Bowl tickets. Based solely on the definition of Runaways and Hunker-downs, these residents were not physically present in the region or were at home. To overcome this inherent difficulty in sampling a resident who is not present, it was necessary to utilize online sampling (to reach those at home) and a lengthy data collection period (nine days) to capture some Runaways before they left. In both cases, it is still possible we under sampled, which relates back to the concern of Matheson and Baade (2006) 
that to calculate the most precise estimate of resident impact with survey techniques, it is necessary to sample residents who are not physically present.

\section{Conclusion}

To date, the largest problem in including residents in impact has been that researchers have named, and thus attempted to capture through surveys, only a few of the possible behaviors of residents. To solve this problem we utilized the core principles of economic impact to build a model with four variables that captured all 72 possible ways residents can affect impact. Next, the model was applied and primary data were collected in the context of Super Bowl 50 to determine the extent to which residents' spending was affected by the event. We analyzed shifts in their spending behavior because of the event (in the four variables spending, business, time, and geography) but also asked what their behavior would have been in the absence of the event.

We found support for the model in determining the effect of changes in resident spending on economic impact for any event and highlight three findings. First, economic impact studies capturing only a few categories of residents (such as Home stayers or Runaways) using only one, two, or three variables are incomplete, resulting in incorrect estimates of resident impact.

Second, we have illustrated that what must be done (gathering data on four variables from residents who are mostly not at an event) is extremely challenging because of the nature of the data being collected (sometimes hypothetical and the reluctance to share monetary information), nearly always cost prohibitive (because of the necessity to find respondents who are geographically dispersed and not in attendance at the event), and researchers have yet to develop a sufficient method to gather the required information for one of the variables (time). Although time is a core variable in economic impact (e.g. historically measured through visitors as time switchers or casuals and through residents as Runaways or Home stayers), it has been 
poorly operationalized by academics and it is very difficult for survey respondents to report accurately. There is a pressing need for considerable academic attention on this aspect of economic impact.

Third, in the case of this Type B event, changes in residents' spending behavior had a negligible effect on impact although it varied between positive and negative depending on the area of impact. Thus, practitioners have the option to engage in the challenging process of gathering data on all four variables on all residents (including those who do not attend the event) or to revert back to the old model of entirely excluding residents from economic impact (e.g., Crompton, 1995, 2006; Wilton \& Nickerson, 2006). The findings from the case of the Super Bowl that the gains and losses are roughly equivalent in all three geographic areas suggest that studies would result in a relatively small error in the overall impact estimation when entirely excluding residents from the calculation of economic impact. However, it is advised that researchers apply the model to other events to determine if these relative equivalencies hold true for multiple event types, especially given the recent focus on smaller events and impact (e.g., Agha \& Taks, 2015; Rascher \& Goldman, 2015). Either way, sport event managers, local organizations, and public authorities need to accurately understand the implications of including or excluding residents in the calculations.

\section{References}

Agha, N. \& Taks, M. A. (2015). A theoretical comparison of the economic impact of large and small events. International Journal of Sport Finance, 10(3), 199-216.

Baade, R. A., \& Matheson, V. A. (2001). Home run or wild pitch? Assessing the economic impact of Major League Baseball's All-Star Game. Journal of Sports Economics, 2(4), 307.

Baade, R. A., Baumann, R. W., \& Matheson, V. A. (2008). Selling the game: Estimating the 
economic impact of professional sports through taxable sales. Southern Economic Journal, 74(3), 794-810.

Bay Area Census. (2016). http://www.bayareacensus.ca.gov/

Breen, H., Bull, A., \& Walo, M. (2001). A comparison of survey methods to estimate visitor expenditure at a local event. Tourism Management, 22(5), 473-479.

Coates, D., \& Depken, C. A. (2009). The impact of college football games on local sales tax revenue: Evidence from four cities in Texas. Eastern Economic Journal, 35(4), 531-547.

Cobb, S., \& Olberding, D. (2007). The importance of import substitution in marathon economic impact analysis. International Journal of Sport Finance, 2(2), 108-118.

Controller's Office. (2016 May 9). Super Bowl 50: City Budget Impact Report. Office of the Controller, City and County of San Francisco. Retrieved from http://sfcontroller.org/sites/default/files/SB\%2050\%20May\%209\%202016.pdf

Crompton, J. L. (1995). Economic impact analysis of sports facilities and events: Eleven sources of misapplication. Journal of Sport Management, 9(1), 14-35.

Crompton, J. L. (2006). Economic impact studies: Instruments for political shenanigans? Journal of Travel Research, 45, 67-82.

Crompton, L. J., \& Howard, D. R. (2013). Costs: The rest of the economic impact story. Journal of Sport Management, 27(5), 379-392.

Davidson, J. (2016, February 1). Super Bowl opening night features players, media and characters. The Sacramento Bee. Retrieved from http://www.sacbee.com/sports/nfl/superbowl/article57855723.html

Davies, L., Coleman, R., \& Ramchandani, G. (2013). Evaluating event economic impact: Rigour versus reality? International Journal of Event and Festival Management, 4(1), 31-42. 
Furnham, A., \& Argyle, M. (1998). The Psychology of Money. New York, NY: Routledge.

Gelan, A. (2003). Local economic impacts: The British Open. Annals of Tourism Research, $30(2), 406-425$.

Getz, D. (1991). Festivals, special events, and tourism. New York: Van Nostrand Reinhold.

Gratton, C., \& Taylor, P. (2000). Economics of sport and recreation. London, U.K.: Spon.

Griffiths, W., Hill, R. C., \& Judge, G. G. (1993). Learning and practicing econometrics. New York, NY: John Wiley \& Sons.

Hodur, N. M., Bangsund, D. A., Leistritz, F. L., \& Kaatz, J. (2006). Estimating the contribution of a multi-purpose event facility to the area economy. Tourism Economics, 12(2), 303-316.

Jones, I. (2015). Research Methods for Sports Studies, $3^{\text {rd }}$ Edition. London: Routledge.

Késenne, S. (2012). The economic impact, costs and benefits of the FIFA World Cup and the Olympic Games: Who wins, who loses? In W. Maennig \& A. S. Zimbalist (Eds.). International handbook on the economics of mega sporting events (pp. 270-278). Cheltenham, UK: Edward Elgar.

Kwiatkowski, G. (2016). Economic impact of event attendees' spending on a host region: A review of the research. Event Management, 20(4), 501-515.

Lee, S. (2016, February 2). 10 ways San Francisco has fumbled its Super Bowl festivities (so far). Newsweek. Retrieved from http://www.newsweek.com/san-francisco-super-bowlsuper-bowl-50-super-bowl-city-421857

Matheson, V. A., \& Baade, R. A. (2006). Padding required: Assessing the economic impact of the Super Bowl. European Sport Management Quarterly, 6(4), 353-374.

Mills, B. M., \& Rosentraub, M. S. (2013). Hosting mega-events: A guide to the evaluation of development effects in integrated metropolitan regions. Tourism Management, 34, 238- 
246.

Neter, J., \& Waksberg, J. (1964). A study of response errors in expenditures data from household interviews. Journal of the American Statistical Association, 59(305), 18-55.

Nielsen (2016, February 8). Super Bowl 50 Draws 111.9 Million TV Viewers. 16.9 Million Tweets. Retrieved from http://www.nielsen.com/us/en/insights/news/2016/super-bowl-50draws-111-9-million-tv-viewers-and-16-9-million-tweets.html

Preuss, H. (2005). The economic impact of visitors at major multi-sport events. European Sport Management Quarterly, 5, 281-301.

Preuss, H., Kurscheidt, M., \& Schütte, N. (2009). Ökonomie des Tourismus durch Sportgroßveranstaltungen: Eine empirische Analyse zur Fußball-Weltmeisterschaft 2006. Wiesbaden: Springer Gabler Verlag.

Rascher, D. A., \& Goldman, M. M. (2015). Tracking the dollars: How economic impact studies can actually benefit managerial decision making. Sport \& Entertainment Review, 1(1), 1519.

Raymos, J. (2016, January 25). PG\&E telling downtown SF employees to work from home, but some businesses left in Super Bowl cold. CBS SF Bay Area, Retrieved from http://sanfrancisco.cbslocal.com/2016/01/25/pge-telling-downtown-sf-employees-to-workfrom-home-but-some-businesses-left-in-super-bowl-cold/

Repucom. (2016). Super Bowl 50 Host Committee Community Impact Study Highlights Positive Impact on San Francisco Bay Area. Retrieved from http://repucom.net/super-bowl-50-hostcommittee-community-impact-study/

Ritchie, B. (1984). Assessing the impact of hallmark events: Conceptual and research issues. Journal of Travel Research, 23(1), 2-11. 
Solberg, H. A., \& Preuss, H. (2007). Major sport events and long-term tourism impacts. Journal of Sport Management, 21(2), 213-234.

Super Bowl 50 Host Committee. (2016). Super Bowl Insight. Retrieved from http://www.cipherbsc.com/superbowlinsight/superbowl50insight/reader.html?contextId=P4 \&isExternal=_external

Shank, M. D., \& Beasley, F. M. (1998). Fan or fanatic: Refining a measure of sports involvement. Journal of Sport Behavior, 21(4), 435-444.

SFMTA (2016). Getting Around During Super Bowl 50. Retrieved from https://www.sfmta.com/sites/default/files/pdfs/2016/SB50-General-Ltr_1.21.16.pdf

Swan, J. E., \& Epley, D. E. (1981). Completion and response rates for different forms of income questions in a mail survey. Perceptual and Motor Skills, 52, 219-22.

Taks, M., Girginov, V., \& Boucher, B. (2006). The outcomes of coattail-marketing: The case of Windsor, Ontario and Super Bowl XL. Sport Marketing Quarterly, 15(4), 232-242.

Taks, M., Késenne, S., Chalip, L., Green, B. C., \& Martyn, S. (2011). Economic impact analysis versus cost benefit analysis: The case of a medium-sized sport event. International Journal of Sport Finance, 6(3), 187-203.

Wilton, J. J., \& Nickerson, N. P. (2006). Collecting and using visitor spending data. Journal of Travel Research, 45(1), 17-25.

Yun, G. W., \& Trumbo, C. W. (2000). Comparative response to a survey executed by post, email, \& web form. Journal of Computer-Mediated Communication, 6(1), 0-0. doi: 10.1111/j.1083-6101.2000.tb00112.x 


\section{Footnotes}

1 Whereas a shift in amount, business, or geography will have an impact, a shift in just timing of residents does not have to have an impact if the other three variables are constant.

2 Reduced productivity is an important issue in large scale events. Mills and Rosentraub (2013) examine this issue in detail. Our method focuses on the Direct Expenditure Approach (DEA) and as such we do not investigate indirect costs.

3 Of the 437 incomplete surveys, 50\% exited the survey once they reached the questions about individual spending data which reinforces our statement about the difficulty collecting spending information. An additional 28\% were not located in the nine-county Bay Area and were thus not our targeted sample. The remaining $22 \%$ opened the survey but answered zero questions. These reasons for elimination do not raise concerns for a non-response bias.

4 Although there were 639 useable responses in the nine-county Bay Area sample, we oversampled in San Francisco and thus used a random number generator to drop 55 responses from San Francisco so that the Bay Area sample achieved the objective stratified sample resulting in 572 .

5 We agree with Crompton (1995) that income multipliers are more useful for a resident to understand the true value of an event to their personal gain or to their elected leaders to make policy decisions to fund events (Crompton, 2006). This study seeks to accomplish neither of these. We analyze how residents shift their spending between industries. The sales, or output multipliers, allow us to calculate the economic impact of this shift (e.g., negative economic impact if a resident shifts behavior from a business with a higher multiplier to a business with a lower multiplier).

6 IMPLAN (http://implan.com/company/) is one of three companies that provide multipliers based on input-output tables from the U.S. Department of Commerce. It is a common tool used in U.S.-based economic impact. See Davies et al. (2013) for more information on input-output and other methods of impact estimation.

7 Of the over 400 industries tracked by IMPLAN, respondents spent in 44 different industries ranging from auto repair to wineries. For the indirect and induced effects the mean $=0.62$ $(\mathrm{SD}=0.23)$, minimum $=0.27$ (gasoline stations), and maximum $=1.55$ (state and local government passenger transit). The only other industry with a multiplier over 1 is performing arts companies.

8 Although San Francisco is also part of the major metropolitan area, it is surrounded on three sides by water and bridges, making individual expenditures in adjacent areas less common. Manhattan is likely an analogous region. While there are common flows of business goods and services in the region, residents are less likely to leave the area to make purchases. 
Table 1. Previous Categories of Residents Affected by Events

\begin{tabular}{|c|c|c|c|}
\hline Previous Cases & Description & Economic Outcome & $\begin{array}{c}\text { Variables Affected by the } \\
\text { Event }\end{array}$ \\
\hline $\begin{array}{l}\text { Home stayers (Preuss, 2005) } \\
\text { Staycation (Getz, 1991) } \\
\text { Vacationing at Home (Cobb \& Olberding, 2007) }\end{array}$ & $\begin{array}{l}\text { Residents forgo a vacation } \\
\text { in order to stay in the } \\
\text { region to partake in the } \\
\text { event }\end{array}$ & $\begin{array}{l}\text { Expenditures are an } \\
\text { economic benefit as they } \\
\text { would not have occurred } \\
\text { locally without the event }\end{array}$ & $\begin{array}{l}\text { - Geographic location of } \\
\text { the spending } \\
\text { - Timing }\end{array}$ \\
\hline Changers (Preuss, 2005) & $\begin{array}{l}\text { Residents replace a pre- } \\
\text { existing vacation with one } \\
\text { that allows them to avoid } \\
\text { the event }\end{array}$ & $\begin{array}{l}\text { No cost or benefit to the } \\
\text { region as the vacation } \\
\text { would have occurred } \\
\text { regardless }\end{array}$ & - Timing \\
\hline
\end{tabular}


Table 2: Economic Impact

\begin{tabular}{|l|l|l|l|}
\hline & Outside the area & Location of Expenditures \\
\hline & & $\begin{array}{c}\text { Not related to } \\
\text { economic impact }\end{array}$ & Economic benefit \\
\hline & Outside the area & Zero economic impact \\
\hline
\end{tabular}

Note. ${ }^{\text {a }}$ Adapted from Preuss (2005). 
Table 3: Theoretical Model of Resident Effects on Economic Impact

\begin{tabular}{|c|c|c|c|c|c|c|}
\hline \multirow[t]{2}{*}{ Spending } & \multirow[t]{2}{*}{ Multiplier } & \multirow[t]{2}{*}{ Time Shift } & \multicolumn{4}{|c|}{ Geography } \\
\hline & & & In-In & In-Out & Out-In & Out-Out \\
\hline \multirow{6}{*}{ More } & \multirow{2}{*}{ Higher } & Yes & + & - & + & \\
\hline & & No & + & - & + & \\
\hline & \multirow{2}{*}{ Same } & Yes & 0 & - & + & \\
\hline & & No & + & - & + & \\
\hline & \multirow{2}{*}{ Lower } & Yes & $?$ & - & + & \\
\hline & & No & $?$ & - & + & \\
\hline \multirow{6}{*}{ Same } & \multirow{2}{*}{ Higher } & Yes & + & - & + & \\
\hline & & No & + & - & + & \\
\hline & \multirow{2}{*}{ Same } & Yes & 0 & - & + & \\
\hline & & No & 0 & - & + & \\
\hline & \multirow{2}{*}{ Lower } & Yes & - & - & + & \\
\hline & & No & - & - & + & \\
\hline \multirow{6}{*}{ Less } & \multirow{2}{*}{ Higher } & Yes & $?$ & - & + & \\
\hline & & No & $?$ & - & + & \\
\hline & \multirow{2}{*}{ Same } & Yes & 0 & - & + & \\
\hline & & No & - & - & + & \\
\hline & \multirow{2}{*}{ Lower } & Yes & - & - & + & \\
\hline & & No & - & - & + & \\
\hline
\end{tabular}

Note. In-In is spending that would have occurred within the area of impact and did, in fact, occur in the area of impact. In-Out is spending that would have occurred within the area of impact but instead shifted out of the area because of the event. Out-In is spending that would have occurred outside the area of impact but instead shifted into the area because of the event. Out-Out is spending that would have occurred outside of the area of impact and did, in fact, occur outside the area of impact.

+ means positive effect, - mean negative effect, 0 means no effect, and blank cells in Out-Out indicate that these resident spending cases are irrelevant because they do not relate to economic impact. 
Table 4. Descriptive Statistics

\begin{tabular}{|c|c|c|c|}
\hline & $\begin{array}{r}\text { Bay Area } \\
(\mathrm{n}=572)\end{array}$ & $\begin{array}{r}\text { San Francisco } \\
(\mathrm{n}=127)\end{array}$ & $\begin{array}{r}\begin{array}{r}\text { Santa Clara } \\
(\mathrm{n}=141)\end{array} \\
\end{array}$ \\
\hline \multicolumn{4}{|l|}{ Gender } \\
\hline Male & $45 \%$ & $54 \%$ & $57 \%$ \\
\hline Female & $55 \%$ & $46 \%$ & $43 \%$ \\
\hline \multicolumn{4}{|l|}{ Household Income } \\
\hline under $\$ 50,000$ & $15 \%$ & $16 \%$ & $12 \%$ \\
\hline$\$ 50,000-\$ 99,999$ & $30 \%$ & $27 \%$ & $39 \%$ \\
\hline$\$ 100,000-\$ 149,999$ & $22 \%$ & $23 \%$ & $23 \%$ \\
\hline$\$ 150,000+$ & $32 \%$ & $34 \%$ & $26 \%$ \\
\hline Average Attitude (7 is highest) & 4.0 & 3.1 & 4.3 \\
\hline Average Age & 43.4 & 38.7 & 42.3 \\
\hline \multicolumn{4}{|l|}{ Awareness } \\
\hline Aware of Super Bowl & $96 \%$ & $98 \%$ & $99 \%$ \\
\hline Attended Super Bowl & $1 \%$ & $1 \%$ & $2 \%$ \\
\hline Average spent to attend Super Bowl ${ }^{\mathrm{a}}$ & $\$ 1300(n=5)$ & $\$ 3500(\mathrm{n}=1)$ & $\$ 1000(n=2)$ \\
\hline Aware of fan festivals & $90 \%$ & $98 \%$ & $88 \%$ \\
\hline Attended fan festivals & $22 \%$ & $35 \%$ & $11 \%$ \\
\hline Average spent to attend fan festivals ${ }^{\mathrm{a}}$ & $\$ 39.07$ & $\$ 28.52$ & $\$ 29.62$ \\
\hline
\end{tabular}

Note. ${ }^{a}$ Average based on those who attended only 
Table 5. Single Variable Shifts

\begin{tabular}{|c|c|c|c|c|c|c|}
\hline \multirow{2}{*}{$\begin{array}{l} \\
\text { SPENDING }\end{array}$} & \multicolumn{2}{|c|}{$\frac{\text { Bay Area }}{n}$} & \multicolumn{2}{|c|}{$\frac{\text { San Francisco }}{\mathrm{n}}$} & \multicolumn{2}{|c|}{$\frac{\text { Santa Clara }}{n}$} \\
\hline & & & & & & \\
\hline Spent More \% & 58 & $10.39 \%$ & 11 & $9.02 \%$ & 22 & $15.94 \%$ \\
\hline Reported How Much More $\$^{a}$ & & $\$ 93.21$ & 11 & $\$ 62.39$ & 22 & $\$ 48.18$ \\
\hline Spent Same \% & 470 & $84.23 \%$ & 93 & $76.23 \%$ & 105 & $76.09 \%$ \\
\hline Spent Less \% & 30 & $5.38 \%$ & 18 & $14.75 \%$ & 11 & $7.97 \%$ \\
\hline Perception How Much Less $\$$ & & $-\$ 30.08$ & 18 & $-\$ 63.07$ & 11 & $-\$ 32.73$ \\
\hline \multicolumn{7}{|l|}{ BUSINESS } \\
\hline Higher multiplier industry $\%$ & 19 & $3.32 \%$ & 8 & $6.30 \%$ & 3 & $2.13 \%$ \\
\hline Same multiplier industry $\%$ & 489 & $85.49 \%$ & 98 & $77.17 \%$ & 115 & $81.56 \%$ \\
\hline Lower multiplier industry $\%$ & 18 & $3.15 \%$ & 8 & $6.30 \%$ & 7 & $4.96 \%$ \\
\hline Average Actual Multiplier ${ }^{\mathrm{b}}$ & 485 & 1.550 & 112 & 1.550 & 109 & 1.518 \\
\hline Average Alternate Multiplier ${ }^{c}$ & 72 & 1.560 & 25 & 1.533 & 27 & 1.554 \\
\hline Average Difference of & & & & & & \\
\hline Actual - Alternate Multiplier & 526 & -0.001 & 114 & 0.008 & 125 & -0.004 \\
\hline \multicolumn{7}{|l|}{ TIME } \\
\hline Changers & 3 & $0.52 \%$ & 2 & $1.57 \%$ & 0 & $0.00 \%$ \\
\hline Qualitative: Shifted time this day & 1 & $0.17 \%$ & 0 & $0.00 \%$ & 0 & $0.00 \%$ \\
\hline Qualitative: Shifted time a different day & 7 & $1.22 \%$ & 1 & $0.79 \%$ & 3 & $2.13 \%$ \\
\hline \multicolumn{7}{|l|}{ GEOGRAPHY $^{\mathrm{d}}$} \\
\hline In-In & 554 & $96.85 \%$ & 109 & $85.83 \%$ & 114 & $80.85 \%$ \\
\hline In-Out & 1 & $0.17 \%$ & 0 & $0.00 \%$ & 8 & $5.67 \%$ \\
\hline Out-In & 0 & $0.00 \%$ & 1 & $0.79 \%$ & 7 & $4.97 \%$ \\
\hline Out-Out & 30 & $5.25 \%$ & 27 & $21.26 \%$ & 17 & $12.06 \%$ \\
\hline Runaways (a specific form of In-Out) & 8 & $1.40 \%$ & 7 & $5.51 \%$ & 3 & $2.13 \%$ \\
\hline
\end{tabular}

Note. The sum of the n's may be lower than the total n's due to missing values

a Average

b This reflects the respondents who actually had transactions "yesterday". Some reported zero spending "yesterday" and thus have no actual multiplier.

${ }^{\mathrm{c}}$ This reflects respondents whose business locations shifted and is comprised of some who had actual spending the prior day and some who had zero spending the prior day.

${ }^{d}$ The sum of percentages can be more than $100 \%$ because a single respondent can have multiple types of geographically shifted expenditures on a single day. 
Table 6. Net Change in Average spending x multiplier for Two Variable Shifts

Bay Area $\quad \underline{\text { San Francisco }} \quad \underline{\text { Santa Clara }}$

$\mathrm{n} n \mathrm{n}$

\section{SPENDING x BUSINESS ${ }^{a}$}

Spent more

Higher multiplier business

$\begin{array}{rrrrrr}15 & \$ 134.12 & 4 & \$ 64.02 & 3 & \$ 92.38 \\ 10 & \$ 34.94 & 0 & & 6 & \$ 47.92 \\ 15 & \$ 239.05 & 3 & \$ 50.16 & 7 & \$ 98.17\end{array}$

Same multiplier business

Lower multiplier business

$\$ 50.16$

$\$ 98.17$

Spent same

Higher multiplier business

$\begin{array}{rrrrrr}0 & & 0 & & 0 & \\ 470 & \$ 0.00 & 93 & \$ 0.00 & 105 & \$ 0.00 \\ 0 & & 0 & & 0 & \end{array}$

Spent less

Same multiplier business

Lower multiplier business

Higher multiplier business

$\begin{array}{lll}4 & -\$ 37.72 & 4\end{array}$

$-\$ 63.46 \quad 0$

Same multiplier business

$\begin{array}{lll}9 & -\$ 31.87 & 5\end{array}$

$-\$ 45.57 \quad 4$

$-\$ 36.38$

Lower multiplier business

$-\$ 5.35 \quad 5$

$-\$ 28.15 \quad 0$

$\begin{array}{llllll}558 & \$ 11.58 & 122 & -\$ 6.59 & 138 & \$ 7.68\end{array}$

Average for full sample

\section{SPENDING $x$ TIME}

Because you spent more than normal did you

$\begin{array}{rrrrrr}63 & & 9 & & 21 & \\ 7 & 11.11 \% & 1 & 11.11 \% & 3 & 14.29 \% \\ 24 & 38.10 \% & 1 & 11.11 \% & 5 & 23.81 \%\end{array}$

Reduce spending past

Reduce spending future

\section{SPENDING $x$ GEOGRAPHY ${ }^{b}$}

In-In

Spent more

Spent same

Spent less

In-Out

Spent more

Spent same

Spent less

Out-In

Spent more

Spent same

Spent less

Out-Out

Spent more

Spent same

Spent less

$\begin{array}{rrrrrr}540 & \$ 11.90 & 104 & -\$ 9.41 & 112 & \$ 6.02 \\ 56 & \$ 139.68 & 10 & \$ 77.13 & 14 & \$ 63.02 \\ 454 & \$ 0.00 & 76 & \$ 0.00 & 94 & \$ 0.00 \\ 30 & -\$ 46.56 & 18 & -\$ 97.22 & 4 & -\$ 59.62 \\ 1 & \$ 30.63 & 0 & & 6 & \$ 106.70 \\ 1 & \$ 30.63 & 0 & & 6 & \$ 106.70 \\ 0 & & 0 & & 0 & \\ 0 & & 0 & & 0 & \\ 0 & & 1 & \$ 3.72 & 7 & -\$ 17.19 \\ 0 & & 1 & \$ 3.72 & 1 & \$ 49.59 \\ 0 & & 0 & & 0 & \\ 0 & & 0 & & 6 & -\$ 28.32 \\ 28 & \$ 0.16 & 26 & \$ 9.69 & 17 & -\$ 7.81 \\ 1 & \$ 4.60 & 2 & \$ 126.00 & 1 & \$ 43.39 \\ 27 & \$ 0.00 & 24 & \$ 0.00 & 14 & \$ 0.00 \\ 0 & & 0 & & 2 & -\$ 88.08\end{array}$

\section{TIME x GEOGRAPHY}

Home stayers (a specific form of Out-In) $5 \quad 0.87 \% \quad 1 \quad 0.79 \%$ $1 \quad 0.71 \%$

a The sum of the n's may be lower than the total n's due to missing values

${ }^{\mathrm{b}} \mathrm{n}$ 's are different from the Geography results in Table 4 because some cases of missing spending or missing multipliers. We remind readers that in the calculation of overall impact In-Out values are negative and Out-Out are irrelevant, as in Table 3. 
Table 7. Net Change in Average spending x multiplier for Three Variable Shifts

\begin{tabular}{|c|c|c|c|c|c|c|}
\hline \multirow{2}{*}{ SPENDING x BUSINESS x GEOGRAPHY } & \multicolumn{2}{|c|}{$\frac{\text { Bay Area }}{\mathrm{n}}$} & \multicolumn{2}{|c|}{$\frac{\text { San Francisco }}{n}$} & \multicolumn{2}{|c|}{$\underline{\mathrm{Santa} \text { Clara }}$} \\
\hline & & & & & & \\
\hline 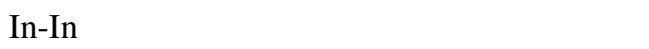 & 540 & $\$ 11.90$ & 104 & $-\$ 9.41$ & 112 & $\$ 6.02$ \\
\hline \multicolumn{7}{|l|}{ Spent more } \\
\hline Higher multiplier business & 15 & $\$ 134.12$ & 4 & $\$ 64.02$ & 1 & $\$ 71.99$ \\
\hline Same multiplier business & 9 & $\$ 35.42$ & 0 & & 4 & $\$ 49.68$ \\
\hline Lower multiplier business & 14 & $\$ 255.80$ & 3 & $\$ 50.16$ & 3 & $\$ 83.11$ \\
\hline \multicolumn{7}{|l|}{ Spent same } \\
\hline Higher multiplier business & 0 & & 0 & & 0 & \\
\hline Same multiplier business & 454 & $\$ 0.00$ & 76 & $\$ 0.00$ & 94 & $\$ 0.00$ \\
\hline Lower multiplier business & 0 & & 0 & & 0 & \\
\hline \multicolumn{7}{|l|}{ Spent less } \\
\hline Higher multiplier business & 4 & $-\$ 37.72$ & 4 & $-\$ 63.46$ & 0 & \\
\hline Same multiplier business & 9 & $-\$ 31.87$ & 5 & $-\$ 45.57$ & 2 & $-\$ 45.96$ \\
\hline Lower multiplier business & 3 & $-\$ 5.35$ & 5 & $-\$ 28.15$ & 0 & \\
\hline In-Out & 1 & $\$ 30.63$ & 0 & & 6 & $\$ 106.70$ \\
\hline Out-In & 0 & & 1 & $\$ 3.72$ & 7 & $-\$ 17.19$ \\
\hline Out-Out & 28 & $\$ 0.16$ & 26 & $\$ 9.69$ & 17 & $-\$ 7.81$ \\
\hline \multicolumn{7}{|l|}{ SPENDING $x$ TIME $x$ GEOGRAPHY } \\
\hline Because you spent less than normal will you & 26 & & 18 & & 8 & \\
\hline Re-spend later in the Bay Area & 8 & $30.77 \%$ & 3 & $16.67 \%$ & 1 & $12.50 \%$ \\
\hline Re-spend later outside the Bay Area & 1 & $3.85 \%$ & 1 & $5.56 \%$ & 1 & $12.50 \%$ \\
\hline
\end{tabular}

Note. Spending and multiplier shifts are truncated for In-Out, Out-In, and Out-Out. We remind readers that in the calculation of overall impact In-Out values are negative and Out-Out are irrelevant, as in Table 3. 
Table 8. Outcome of Resident Effects on Economic Impact

\begin{tabular}{|c|c|c|c|c|c|c|c|c|c|c|}
\hline \multirow[t]{2}{*}{ Geography } & \multirow[t]{2}{*}{ Spending } & \multirow[t]{2}{*}{ Multiplier } & \multirow{2}{*}{$\begin{array}{l}\text { Time } \\
\text { Shift }\end{array}$} & \multirow{2}{*}{$\begin{array}{c}\text { Theoretical } \\
\text { Outcome }\end{array}$} & \multicolumn{6}{|c|}{ Samples } \\
\hline & & & & & \multicolumn{2}{|c|}{$\begin{array}{c}\text { Bay Area } \\
(n=528)\end{array}$} & \multicolumn{2}{|c|}{$\begin{array}{c}\text { San Francisco } \\
(n=118)\end{array}$} & \multicolumn{2}{|c|}{$\begin{array}{c}\text { Santa Clara } \\
(n=121)\end{array}$} \\
\hline \multirow[t]{18}{*}{ In-In } & \multirow{6}{*}{ More } & \multirow{2}{*}{ Higher } & Yes & + & $1.1 \%$ & $\$ 174.53$ & $0.0 \%$ & & $0.0 \%$ & \\
\hline & & & $\mathrm{No}$ & + & $1.2 \%$ & $\$ 128.93$ & $0.8 \%$ & $\$ 114.51$ & $7.0 \%$ & $\$ 71.99$ \\
\hline & & \multirow{2}{*}{ Same } & Yes & 0 & $0.7 \%$ & $\$ 35.21$ & $0.0 \%$ & & $0.7 \%$ & $\$ 43.76$ \\
\hline & & & $\mathrm{No}$ & + & $0.5 \%$ & $\$ 51.66$ & $0.0 \%$ & & $2.1 \%$ & $\$ 51.66$ \\
\hline & & \multirow{2}{*}{ Lower } & Yes & $?$ & $0.9 \%$ & $\$ 93.82$ & $0.8 \%$ & $\$ 85.21$ & $0.7 \%$ & $\$ 144.40$ \\
\hline & & & $\mathrm{No}$ & $?$ & $1.1 \%$ & $\$ 481.90$ & $0.0 \%$ & & $0.7 \%$ & $\$ 79.09$ \\
\hline & \multirow{6}{*}{ Same } & \multirow{2}{*}{ Higher } & Yes & + & $0.0 \%$ & & $0.0 \%$ & & $0.0 \%$ & \\
\hline & & & $\mathrm{No}$ & + & $0.0 \%$ & & $0.0 \%$ & & $0.0 \%$ & \\
\hline & & \multirow{2}{*}{ Same } & Yes & 0 & $79.4 \%$ & $\$ 0.00$ & $59.8 \%$ & $\$ 0.00$ & $67.4 \%$ & $\$ 0.00$ \\
\hline & & & No & 0 & $0.0 \%$ & & $0.0 \%$ & & $0.0 \%$ & \\
\hline & & \multirow{2}{*}{ Lower } & Yes & - & $0.0 \%$ & & $0.0 \%$ & & $0.0 \%$ & \\
\hline & & & No & - & $0.0 \%$ & & $0.0 \%$ & & $0.0 \%$ & \\
\hline & \multirow{6}{*}{ Less } & \multirow{2}{*}{ Higher } & Yes & $?$ & $0.4 \%$ & $-\$ 26.44$ & $0.0 \%$ & & $0.0 \%$ & \\
\hline & & & $\mathrm{No}$ & $?$ & $0.4 \%$ & $-\$ 49.00$ & $3.2 \%$ & $-\$ 63.46$ & $0.0 \%$ & \\
\hline & & \multirow{2}{*}{ Same } & Yes & 0 & $0.4 \%$ & $-\$ 15.32$ & $0.8 \%$ & $-\$ 7.66$ & $0.7 \%$ & $-\$ 22.98$ \\
\hline & & & $\mathrm{No}$ & - & $0.9 \%$ & $-\$ 41.91$ & $2.4 \%$ & $-\$ 196.53$ & $0.7 \%$ & $-\$ 68.93$ \\
\hline & & \multirow{2}{*}{ Lower } & Yes & - & $0.0 \%$ & & $0.8 \%$ & $-\$ 118.11$ & $0.0 \%$ & \\
\hline & & & $\mathrm{No}$ & - & $0.5 \%$ & $-\$ 5.35$ & $3.2 \%$ & $-\$ 5.65$ & $0.0 \%$ & \\
\hline In-Out & & \multicolumn{2}{|l|}{ All Cases } & - & $0.2 \%$ & $\$ 30.63$ & $0 \%$ & & $5.7 \%$ & $\$ 106.47$ \\
\hline Out-In & & \multicolumn{2}{|l|}{ All Cases } & + & $0.0 \%$ & & $0.8 \%$ & $\$ 3.72$ & $5.0 \%$ & $-\$ 25.94$ \\
\hline Out-Out & & \multicolumn{2}{|l|}{ All Cases } & & $4.9 \%$ & & $20.5 \%$ & & $1.4 \%$ & \\
\hline
\end{tabular}


Table 9. Percent of Sample Leading to Positive, Negative, and Neutral Effects

\begin{tabular}{lccc}
\hline Effect on impact & Bay Area & San Francisco & Santa Clara \\
\hline Positive & $5 \%$ & $3 \%$ & $11 \%$ \\
Neutral & $87 \%$ & $65 \%$ & $80 \%$ \\
Negative & $2 \%$ & $10 \%$ & $7 \%$ \\
Not related to impact & $5 \%$ & $22 \%$ & $2 \%$ \\
\hline
\end{tabular}




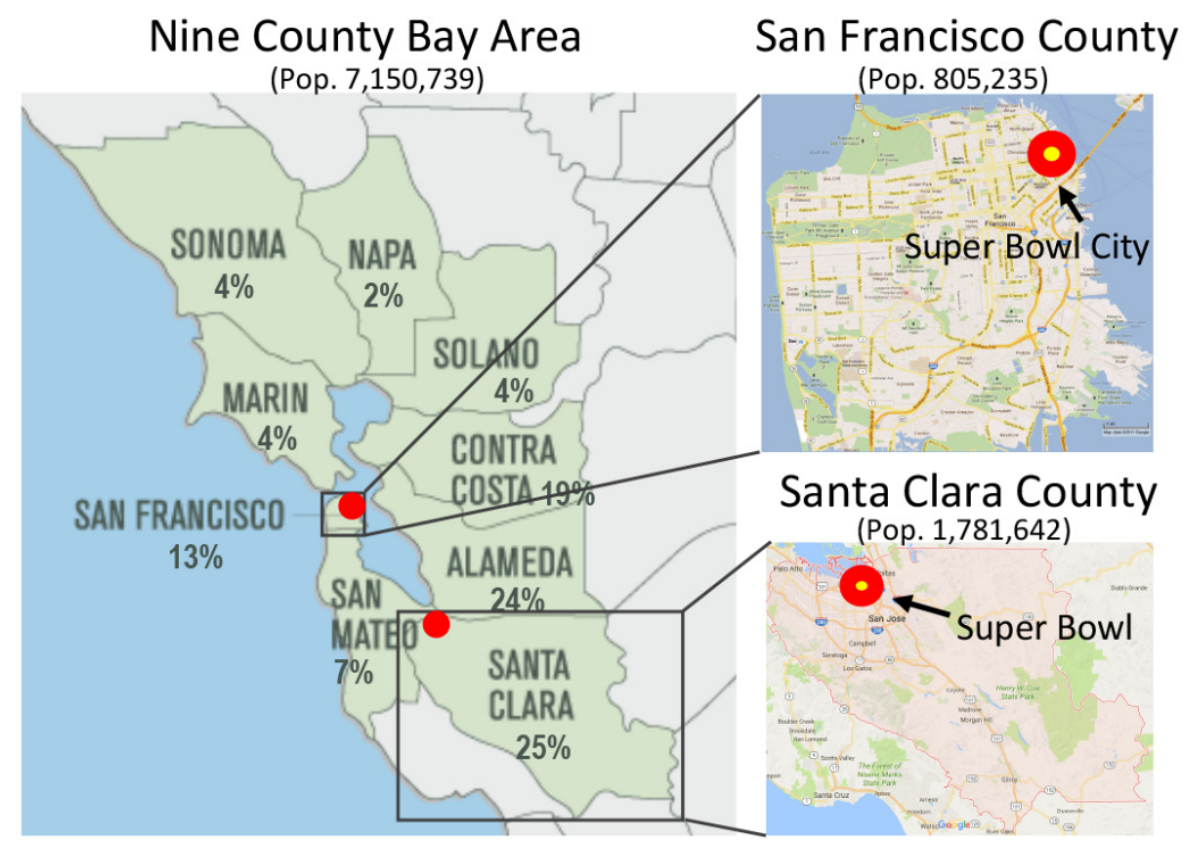

Figure 1. Maps of three geographic areas under investigation. 